\title{
ANALISA PENGARUH PENAMBAHAN ASAM TARTRAT TERHADAP PEMBENTUKAN KERAK DI DALAM PIPA PENGEBORAN MINYAK BUMI
}

\author{
Fahmy Fatra ${ }^{1}$, Joko Suwignyo ${ }^{2}$ \\ ${ }^{1}$ Fakultas sains dan teknologi, Universitas Ivet. \\ Email: fathrafahmi@gmail.com \\ ${ }^{2}$ Fakultas sains dan teknologi, Universitas Ivet.
}

\begin{abstract}
ABSTRAK
Kerak yang ditimbulkan pada pipa pengeboran minyak bumi yaitu kerak barium sulfate $\left(\mathrm{BaSO}_{4}\right)$. Kerak ini merupakan masalah serius yang banyak dihadapi pada proses pengeboran minyak bumi dan gas di laut lepas. Masalah serius tersebut mengakibatkan penyempitan diameter dalam pipa, dan berkurangnya transfer air pada pipa sehingga dapat berakibat pipa menjadi pecah. Pada penelitian ini menjelaskan proses pengerakan barium sulfat $\left(\mathrm{BaSO}_{4}\right)$ pada aliran laminer disistem perpipaan. Larutan barium sulfat $\left(\mathrm{BaSO}_{4}\right)$ dibuat dengan cara mencampurkan larutan equimolar barium chloride $\left(\mathrm{BaCl}_{2}\right)$ dan natrium sulfate $\left(\mathrm{Na}_{2} \mathrm{SO}_{4}\right)$. Parameter yang diteliti adalah variasi konsentrasi barium sulfate yaitu 1000 ppm, 1500 ppm, 2000 ppm, 2500 ppm, dan 3000 ppm, laju aliran $30 \mathrm{ml} /$ menit (konstan), temperatur $20^{\circ} \mathrm{C}$ (konstan) dan konsentrasi aditif asam tartrat $(0,5,10$ ppm). Proses pembentukan kerak barium sulfate $\left(\mathrm{BaSO}_{4}\right)$ dimonitor dengan alat konduktivity meter. Hasil kerak barium sulfate $\left(\mathrm{BaSO}_{4}\right)$ yang diperoleh baik sebelum penggunaan aditif asam tartrat $\left(\mathrm{C}_{4} \mathrm{H}_{6} \mathrm{O}_{6}\right)$ maupun setelah dicampur aditif asam tartrat $\left(\mathrm{C}_{4} \mathrm{H}_{6} \mathrm{O}_{6}\right)$ kemudian dikeringkan dan dikarakterisasi dengan analisa SEM dan XRD. Dari hasil pengujian SEM dapat disimpulkan bahwa larutan tanpa menggunakan aditif kristalnya akan mudah menempel di pipa dikarenakan bentuknya yang tumpul sehingga kristal mudah untuk menempel di pipa. Sedangkan larutan dengan menggunakan aditif bentuk kristalnya runcing itu artinya kristal akan sulit untuk menempel di pipa sehingga dapat menghambat pertumbuhan kerak di dalam pipa. Sedangkan dari hasil uji XRD kerak yang terjadi yaitu kerak barium sulfate (barite).
\end{abstract}

Kata Kunci: Barium sulfate, konsentrasi larutan, asam tartrat

\begin{abstract}
The scale that is generated in the petroleum drilling pipe is the barium sulfate $\left(\mathrm{BaSO}_{4}\right)$ scale. This scale is a serious problem faced by many in the process of drilling for oil and gas in the high seas. This serious problem results in narrowing of the inner diameter of the pipe, and reduced water transfer to the pipe, which can result in pipe rupture. This research describes the process of scavenging barium sulfate (BaSO $\left.{ }_{4}\right)$ in laminar flow in a piping system. A solution of barium sulfate $\left(\mathrm{BaSO}_{4}\right)$ is prepared by mixing an equimolar solution of barium chloride $\left(\mathrm{BaCl}_{2}\right)$ and sodium sulfate $\left(\mathrm{Na}_{2} \mathrm{SO}_{4}\right)$. The parameters studied were variations in the concentration of barium sulfate, namely 1000 ppm, 1500 ppm, 2000 ppm, 2500 ppm, and 3000 ppm, flow rate of $30 \mathrm{ml} /$ minute (constant), temperature $20^{\circ} \mathrm{C}$ (constant) and the concentration of additive tatric acid $(0,5,10$ ppm). The process of calculating barium sulfate $\left(\mathrm{BaSO}_{4}\right)$ is monitored with a conductivity meter. The results of barium sulfate $\left(\mathrm{BaSO}_{4}\right)$ scale obtained both before the use of tatric acid additive $\left(\mathrm{C}_{4} \mathrm{H}_{6} \mathrm{O}_{6}\right)$ and after being mixed with tartaric acid additive $\left(\mathrm{C}_{4} \mathrm{H}_{6} \mathrm{O}_{6}\right)$ were then dried and characterized by SEM and XRD analysis. From the SEM test results, it can be concluded that the solution without the use of crystalline additives will easily stick to the pipe due to its blunt shape so that the crystal is easy to stick to the pipe. Whereas the solution using an additive in the form of tapered crystals means that the crystals will be difficult to stick to the pipe so that it can inhibit scale growth in the pipe. Whereas from the XRD test results the crust that occurs is the barium sulfate (barite) scale.
\end{abstract}

Keywords: Barium sulfate, solution concentration, tartaric acid 


\section{PENDAHULUAN}

Penyebab terbentuknya endapan kerak pada pipa-pipa saluran industri adalah terdapatnya senyawa-senyawa pembentuk kerak dalam air dengan jumlah yang melebihi kelarutannya pada keadaan kesetimbangan. Sehingga dapat memperkecil diameter dalam pipa yang berakibat pada terhambatnya aliran fluida pada sistem pipa tersebut. Terganggunya aliran fluida tersebut menyebabkan suhu semakin meningkat dan tekanan semakin tinggi sehingga kemungkinan pipa akan pecah (Asnawati, 2001). Pembentukan kerak dapat dicegah dengan cara pelunakan dan pembebasan mineral air, akan tetapi penggunaan air bebas mineral dalam industry membutuhkan biaya yang lebih tinggi (Sousa M.F, dkk, 2014).

Kerak barium sulfate (BaSO4) adalah kerak yang diketahui sangat umum ditemukan dalam produksi minyak bumi (F. Jones, dkk, 2002). Kerak barium sulfate tidak seperti kerak kalsium sulfate dan kerak kalsium karbonat, kerak barium sulfate merupakan kerak yang paling keras yang ditemukan di system produksi minyak dan gas lepas pantai. Kerak barium sulfate (BaSO4) adalah kerak yang paling sulit dihilangkan karena zat yang sangat tidak larut (kelarutan hanya dalam air $2 \mathrm{mg} / \mathrm{liter}$ dalam air). Karena kelarutan relative rendah dalam air, endapan kerak barium sulfate dengan mudah terbentuk dari air garam setelah batas kelarutannya telah terlampaui dan tidak dapat dihilangkan dengan perlakuan asam (Emel Akyol, dkk, 2016).

Faktor-faktor yang mempengaruhi endapan kerak dan pertumbuhan kristal adalah supersaturasi, temperature, tekanan, kekuatan ion, evaporation, waktu kontak dan $\mathrm{pH}$. Variabel pembentukan kerak barium sulfate (BaSO4) dipengaruhi oleh temperature dan tekanan. Kerak barium sulfate (BaSO4) pengendapannya sangat mudah terjadi pada pipa produksi minyak dan gas di lepas pantai karena kondisi termodinamika dan kinetic endapan (Amer Barder Bin Merdhah dkk, 2009). Sifat kerak barium sulfate berbeda dengan kerak kalsium karbonat. Kelarutan pada kerak barium sulfate meningkat dengan suhu, berbanding terbalik dengan kerak kalsium karbonat. Kelarutan barium sulfate lebih rendah dibandingkan dengan kalsium karbonat (Robert J. Ferguson, dkk, 2010).

Kerak juga dapat dicegah menggunakan aditif asam sebagai inhibitor untuk menurunkan $\mathrm{pH}$ larutan, mengontrol impurity ion senyawa anorganik serta komposisi morfologi dan fase kristal BaSO4 dan mencegah proses nucleation, pertumbuhan kristal BaSO4. Namun menghilangkan kerak menggunakan asam dengan konsentrasi tinggi tidak efektif karena dapat meningkatnya laju korosi yang cukup tinggi, sementara itu penggunaan inhibitor kimia yang mengandung fosfonat dan karboksilat cukup berbahaya karena akan merubah kualitas air [7]. Dikarenakan air didalam pipa tidak digunakan untuk minum maupun untuk kebutuhan sehari-hari melainkan digunakan untuk pengeboran tanah dalam produksi minyak bumi dan gas, maka inhibitor yang paling efektif digunakan dalam pengendalian kerak barium sulfate (BaSO4) yaitu berasal dari bahan kimia anorganik fosfonat, campuran organophosphorous, dan organik polimer [8]. Akan tetapi bahan fosfonat merupakan bahan kimia yang sifatnya tidak ramah lingkungan. Sehingga hal inilah yang mendasari untuk dilakukan suatu penelitian lebih lanjut mengenai inhibitor kerak baru yang lebih efektif dan ramah lingkungan untuk mencegah kerak barium 
sulfate (BaSO4) yaitu dengan inhibithor asam tartrat.

Konsentrasi memiliki pengaruh yang signifikan terhadap pertumbuhan kerak barium sulfate (BaSO4) (Amer Barder Bin Merdhah dkk, 2009). Untuk mempelajari efek konsentrasi terhadap pertumbuhan kerak barium sulfate (BaSO4) maka laju alir (tekanan) pada pipa dibuat konstan. Oleh karena itu, pada penelitian ini menggunakan asam tartrat sebagai inhibitor dengan parameter variasi konsentrasi larutan dan laju alir yang konstan diharapkan dapat mengetahui pengaruh aditif asam tartrat sebagai penghambat laju pertumbuhan kerak barium sulfate (BaSO4) yang terbentuk di dalam pipa-pipa industry minyak bumi dan gas di lepas pantai.

\section{METODE PENELITIAN}

\section{Material}

Bahan yang digunakan dalam penelitian ini yaitu Kristal $\mathrm{BaCl}_{2}$ (Barium Cloride Dihydrad) grade analitik, Kristal $\mathrm{Na}_{2} \mathrm{SO}_{4}$ (Natrium Sulfate) grade analitik, $\mathrm{H}_{2} \mathrm{O}$ (aquades), dan Asam Tartrat $\left(\mathrm{C}_{4} \mathrm{H}_{6} \mathrm{O}_{6}\right)$ grade analitik sebagai aditif. Semua bahan tersebut diatas didapatkan di Toko Kimia Indrasari Semarang.

\section{Metode}

Proses penelitian mengikuti diagram flow chart pada Gambar 2. Variasi konsentrasi larutan yang digunakan yaitu sebesar 1000 ppm, 1500 ppm, 2000 ppm, 2500 ppm, dan 3000 ppm. Laju alir dan temperature yang digunakan dalam penelitian konstan masing-masing sebesar $30 \mathrm{ml} / \mathrm{menit}$ dan $20^{\circ} \mathrm{C}$. Sedangkan konsentrasi aditif asam tartrat yang digunakan yaitu 0 ppm, 5 ppm, dan $10 \mathrm{ppm}$. Hasil kerak yang terbentuk tanpa menggunakan aditif maupun dengan menggunakan aditif kita uji dengan uji
SEM dan XRD. Uji SEM tanpa menggunakan aditif dan menggunakan aditif dilakukan untuk mengetahui perubahan morfologi pada kerak barium sulfate $\left(\mathrm{BaSO}_{4}\right)$. Uji XRD dilakukan untuk mengetahui bahwa kerak yang terbentuk dari hasil penelitian ini adalah kerak barium sulfate $\left(\mathrm{BaSO}_{4}\right)$. Adapun alat yang digunakan untuk penelitian pada gambar 1 dengan menggunakan skala ml untuk setiap larutan yang digunakan untuk uji coba.

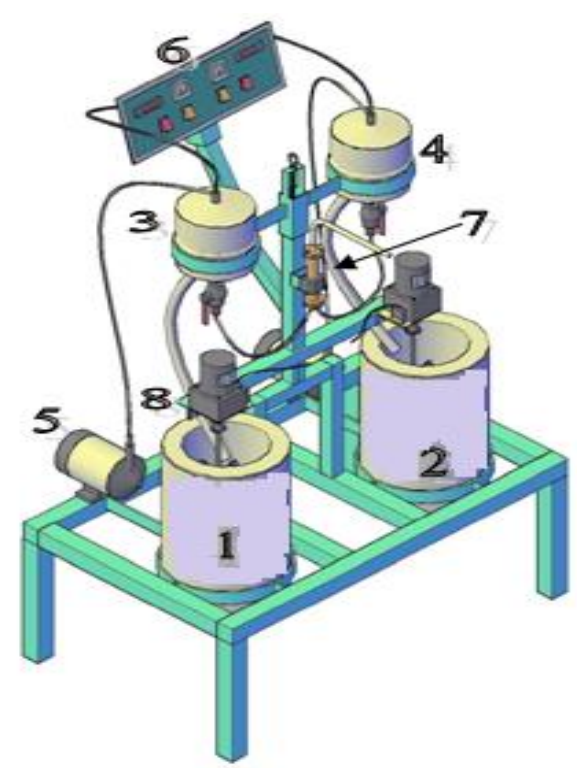

Gambar 1. Alat Penelitian
Keterangan Gambar:
1. Bejana bawah $\mathrm{BaCl}_{2}$
2. Bejana bawah $\mathrm{Na}_{2} \mathrm{SO}_{4}$
3. Bejana atas $\mathrm{BaCl}_{2}$
4. Bejana atas $\mathrm{Na}_{2} \mathrm{SO}_{4}$
5. Pompa
6. Temperatur control
7. Kupon dan rumahnya
8. Mixer 


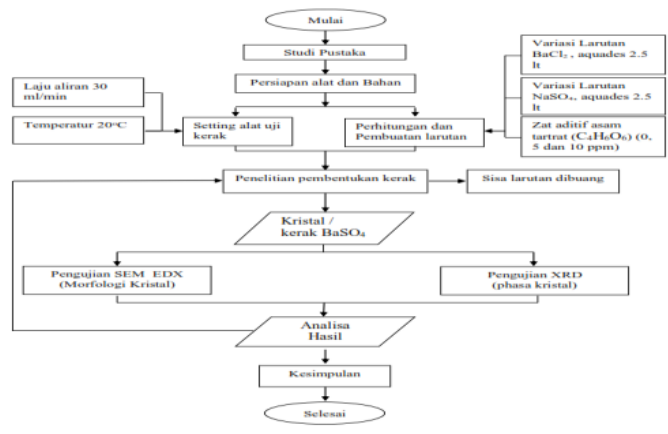

Gambar 2. Diagram Flow Chart Penelitian

\section{Langkah Penelitian}

Penelitian ini dilakukan untuk mengkaji pembentukan kerak pada pipa beraliran laminer dengan melalui tahapan tahapan sebagai berikut ini :

\subsection{Pengujian Alat}

Pengujian alat yaitu yang pertama pengujian laju alir dengan kecepatan 30 $\mathrm{ml} /$ menit. Langkah pertama pengujian laju alir adalah dengan mengatur beda ketinggian $(\Delta \mathrm{h})$ yaitu selisih ketinggian antara permukaan larutan pada bejana (3 dan 4) dengan saluran pengeluaran aliran larutan pada kupon. Semakin tinggi beda ketinggiannya maka laju alirannya semakin besar. Pada pengujian ini bejana 3 dan 4 diatur pada posisi tertentu kemudian larutan yang keluar dari saluran pembuangan diukur volumenya dengan gelas ukur selama 60 detik.

Pengujian alat yang kedua yaitu pengujian temperatur dilakukan dengan tujuan untuk mendapatkan temperatur larutan seperti yang telah direncanakan dan selalu sama selama proses percobaan berlangsung. Temperature yang digunakan dalam penelitian ini yaitu $20^{\circ} \mathrm{C}$.

Pengujian yang ketiga yaitu pengujian untuk pengambilan data dengan conductivity meter. Conductivity meter berfungsi untuk mengukur konduktifitas larutan.

\subsection{Pembuatan larutan $\mathrm{BaCl}_{2}, \mathrm{Na}_{2} \mathrm{SO}_{4}$ dan asam tartrat $\left(\mathrm{C}_{4} \mathrm{H}_{6} \mathrm{O}_{6}\right)$ sebagai aditif}

Untuk membuat larutan $\mathrm{BaCl}_{2}$ dengan $\mathrm{Na}_{2} \mathrm{SO}_{4}$ pertama-tama dilakukan perhitungan konsentrasi barium sulfate yang direncanakan yaitu 3000 ppm $\mathrm{Ba}^{2+}$ dengan laju alir sebesar $30 \mathrm{ml} /$ menit. Variasi konsentrasi barium sulfate yang digunakan dalam penelitian ini yaitu 1000 ppm, 1500 ppm, 2000 ppm, 2500 ppm, dan 3000 ppm. Konsentrasi aditif asam tartrat yang digunakan yaitu $0 \mathrm{ppm}, 5 \mathrm{ppm}$, 10 ppm. Adapun hasil perhitungan seluruhnya dapat dilihat pada tabel 1 .

Tabel 1. Larutan Percobaan

\begin{tabular}{|c|c|c|c|c|}
\hline $\begin{array}{c}\text { Konsentrasi } \\
\text { Larutan (ppm) }\end{array}$ & $\begin{array}{c}\mathrm{BaCl}_{2} \\
\text { (gram) }\end{array}$ & $\begin{array}{l}\mathrm{Na}_{2} \mathrm{SO}_{4} \\
(\text { gram) }\end{array}$ & $\begin{array}{c}\mathrm{H}_{4} \mathrm{C}_{6} \mathrm{O}_{6} \\
5 \mathrm{ppm} \\
(\text { gram })\end{array}$ & $\begin{array}{c}\mathrm{H}_{4} \mathrm{C}_{6} \mathrm{O}_{6} \\
10 \mathrm{ppm}(\mathrm{gram})\end{array}$ \\
\hline 1000 & 12,472 & 6,127 & 0,03 & 0,06 \\
\hline 1500 & 17,529 & 9,096 & 0,03 & 0,06 \\
\hline 2000 & 22,629 & 12,192 & 0,03 & 0,06 \\
\hline 2500 & 27,721 & 15,279 & 0,03 & 0,06 \\
\hline 3000 & 32,011 & 18,465 & 0,03 & 0,06 \\
\hline
\end{tabular}

\subsection{Persiapan Pipa Uji}

Kupon adalah komponen yang dipasang pada sistem aliran dengan harapan disitulah akan terjadi pengendapan kerak barium sulfate untuk diteliti. Kupon terbuat dari stainless steel yang dikerjakan melalui proses machining menjadi bentuk pipa dengan ukuran panjang $31 \mathrm{~mm}$, diamater dalam $13 \mathrm{~mm}$ dan diameter luar $20 \mathrm{~mm}$. Jumlah kupon ada lima buah yang dipasang didalam rumah kupon. Gambar kupon dapat dilihat pada gambar 3 dibawah ini

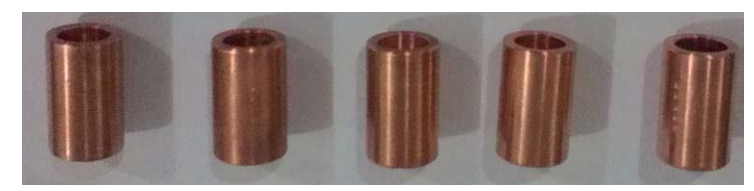

Gambar 3. Kupon 
Online: http://ojs.upy.ac.id/ojs/index.php/jatve

\section{Pengambilan Data}

Pengambilan data (percobaan) dilakukan dengan laju alir $30 \mathrm{ml} / \mathrm{menit}$ dan variasi konsentrasi larutan 1000 ppm, 1500 ppm, 2000 ppm, 2500 ppm, dan 3000 ppm. Temperature yang digunakan sebesar $20{ }^{\circ} \mathrm{C}$ dan konsentrasi aditif asam tartrat $(0,5,10 \mathrm{ppm})$, dimana tiap variasi konsentrasi larutan barium sulfate dan aditif dilakukan sebanyak tiga kali percobaan, sehingga total percobaan yang dilakukan sebanyak 15 kali. Larutan $\mathrm{Na}_{2} \mathrm{SO}_{4}$ dan $\mathrm{BaCl}_{2}$ masing-masing sebanyak 3,2 liter dimasukkan masingmasing ke dalam bejana 1 dan bejana 2 . Setelah itu pompa dihidupkan dan larutan naik mengisi sampai batas atas bejana 3 dan bejana 4 dan kemudian pompa dimatikan. Beberapa saat kemudian pompa dihidupkan kembali dan larutan mulai mengisi kupon, dengan demikian percobaan telah dimulai. Pencatat waktu pada saat yang sama juga diaktifkan dimana setiap dua menit sekali perlu dilakukan pengukuran terhadap konduktivitas larutan. Untuk melakukan pengukuran konduktivitas larutan, larutan yang keluar dari kupon ditampung pada bejana kecil yang terbuat dari plastik dan sesegera mungkin elektroda conductivitymeter dimasukkan. Conductivitymeter akan mengukur nilai konduktivitas larutan (pembacaan digital mulai berjalan dari nol kemudian naik sampai akhirnya berhenti). Angka yang terakhir inilah yang dicatat, dan seterusnya dilakukan berulang-ulang setiap dua menit. Setelah dua jam, pompa dihentikan dan saluran menuju kupon dilepas. Satu jam kemudian kupon diambil dari rumah kupon dan dikeringkan dalam oven dengan suhu $60^{\circ} \mathrm{C}$ selama dua belas jam. Penimbangan massa kerak dilakukan pada waktu kerak masih menempel pada kupon.
Selanjutnya selisih massa kupon dengan kerak dikurangi massa kupon tanpa kerak adalah massa kerak itu sendiri.

\section{Pengujian SEM dan XRD}

Pengujian SEM dilakukan untuk mengetahui morfologi kristal sedangkan pengujian XRD dilakukan untuk membuktikan bahwa kerak yang terbentuk dari hasil penelitian ini adalah kerak barium sulfate

\section{HASIL PENELITIAN}

\section{Analisa Waktu Induksi}

Waktu induksi adalah waktu yang dibutuhkan oleh ion-ion dalam larutan untuk bereaksi sehingga membentuk inti kristal yang pertama kali. Metode yang sering digunakan untuk menentukan waktu induksi adalah dengan cara mengukur konduktivitas larutan yang keluar dari pipa uji.

Analisa yang dilakukan yaitu tentang waktu yang dibutuhkan oleh senyawa barium sulfat untuk membentuk inti Kristal pertama kali. Waktu induksi terjadi ditandai dengan menurunnya nilai konduktivitas larutan secara tajam yang menandakan bahwa ion barium telah bereaksi dengan ion sulfate dan mengendap membentuk kerak. Waktu induksi untuk konsentrasi larutan 1000 ppm, 1500 ppm, 2000 ppm, 2500 ppm dan 3000 ppm masing-masing menunjukkan nilai yang berbeda seperti yang terlihat pada Gambar 4 dibawah ini. 


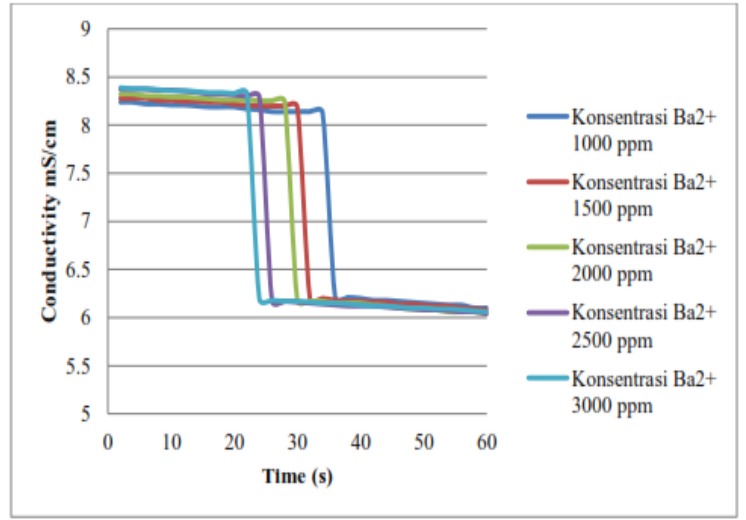

Gambar 4. Grafik hubungan antara konduktivitas dengan waktu pada variasi konsentrasi larutan $\mathrm{Ba}^{2+}$ ( 1000, 1500, 2000, 2500, 3000 ppm )

Dari gambar diatas dapat disimpulkan bahwa semakin tinggi konsentrasi larutan $\mathrm{Ba}^{2+}$ semakin cepat waktu induksi terjadi, semakin kecil konsentrasi larutan $\mathrm{Ba}^{2+}$ maka semakin lama waktu induksi terjadi dengan kata lain semakin lama inti kristal terbentuk.

\section{Massa Kristal}

Penelitian ini menggunakan lima variasi konsentrasi $\mathrm{Ba}^{2+}$ dalam larutan (1000, 1500, 2000, 2500, 3000 ppm), dan tiga konsentrasi berbeda dari asam tartarat $(0,5$, 10 ppm) dipilih. Tabel 2 menyajikan skala massa barit yang terbentuk dari larutan. Hal ini menunjukkan bahwa semakin banyak konsentrasi $\mathrm{Ba}^{2+}$ yang tersedia dalam larutan tersebut, semakin banyak massa kerak yang dihasilkan dalam sistem perpipaan. Namun demikian, semakin banyak asam tartarat yang ditambahkan, pertumbuhan kristal barit terhambat. Akibatnya, produk massal timbangan berkurang dengan adanya aditif.
Tabel 2. Endapan massa kerak dari luratan dengan penambahan asam tartrat

\begin{tabular}{cccc}
\hline No & $\begin{array}{c}\mathbf{C o n c e n t r a t i o n}_{\mathbf{B a}^{2+}(\mathbf{p p m})} \\
\text { (T) }\end{array}$ & $\begin{array}{c}\text { Tartaric } \\
\text { Acid } \\
(\mathbf{p p m})\end{array}$ & $\begin{array}{c}\text { Mass of } \\
\text { scale } \\
(\mathbf{g r a m})\end{array}$ \\
\hline 1 & 1000 & 0 & 0.087 \\
2 & 1000 & 5 & 0.083 \\
3 & 1000 & 10 & 0.075 \\
4 & 1500 & 0 & 0.105 \\
5 & 1500 & 5 & 0.101 \\
6 & 1500 & 10 & 0.094 \\
7 & 2000 & 0 & 0.129 \\
8 & 2000 & 5 & 0.122 \\
9 & 2000 & 10 & 0.115 \\
10 & 2500 & 0 & 0.159 \\
11 & 2500 & 5 & 0.153 \\
12 & 2500 & 10 & 0.145 \\
13 & 3000 & 0 & 0.185 \\
14 & 3000 & 5 & 0.177 \\
15 & 3000 & 10 & 0.173 \\
\hline
\end{tabular}

\section{Analisa Morfologi}

Analisa morfologi dilakukan untuk mengetahui bentuk kristal yang terbentuk apakah benar-benar bentuk kristal barium sulfate atau tidak. Bentuk kristal barium sulfate hanya ada satu yaitu barite. Berikut adalah hasil pengujian SEM yang dilakukan pada konsentrasi 3000 ppm tanpa penambahan aditif (gambar 5) dan dengan penambahan aditif 10 ppm (gambar 6).

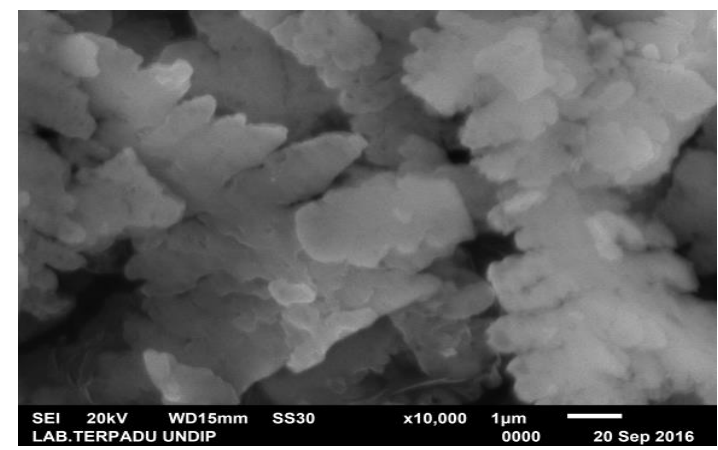

Gambar 5. Morfologi kristal dengan konsentrasi larutan 3000 ppm tanpa aditif 


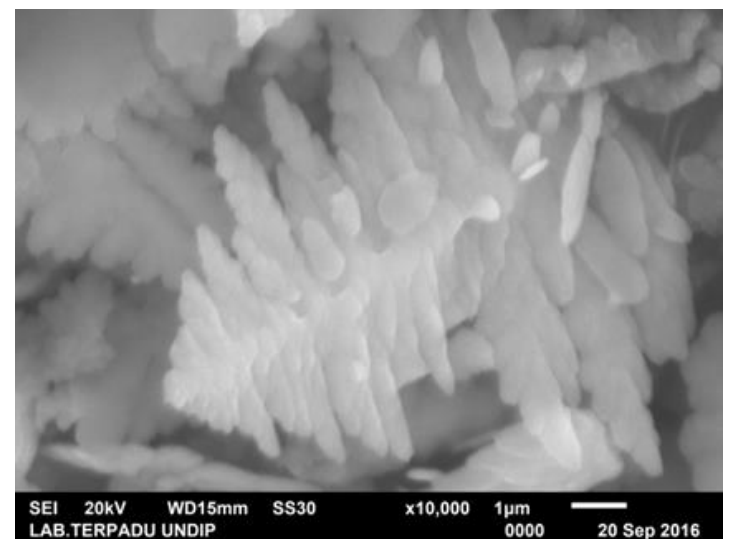

Gambar 6. Morfologi kristal dengan konsentrasi larutan 3000 ppm dengan aditif 10 ppm

Dari hasil pengujian SEM terlihat bahwa tanpa adanya aditif bentuk dari morfologi kristal yaitu tumpul sedangkan dengan menggunakan aditif $10 \mathrm{ppm}$ terlihat bahwa bentuk morfologi kristal runcing. Dari hasil pengujian SEM dapat disimpulkan bahwa larutan tanpa menggunakan aditif kristal yang terbentuk akan mudah menempel di pipa dikarenakan bentuknya yang tumpul sehingga kristal mudah untuk menempel di pipa. Sedangkan larutan dengan menggunakan aditif kristal yang terbentuk adalah runcing itu artinya kristal akan sulit untuk menempel di pipa sehingga dapat menghambat pertumbuhan kerak di dalam pipa. Hasil penelitian ini sejalan dengan penelitian yang dilakukan oleh G. Ivanto dkk, 2017 bahwa dengan penambahan aditif dapat menghambat pertumbuhan kerak barium sulfate.

\section{Analisa Fasa Kristal}

Analisa fasa kristal kalsium karbonat dilakukan untuk mengetahui fasa kristal yang terbentuk apakah benar-benar kristal barium sulfate atau tidak dengan cara dilakukan pengujian XRD.
Data hasil pengukuran XRD ini kemudian biasanya dibandingkan dengan referensi JCPDS-ICDD $\mathrm{BaSO}_{4}$ (04-0125411). Apabila menunjukkan nilai kesamaan antara sudut $2 \theta$ dan intesitasnya yang tertinggi maka spesimen hasil penelitian merupakan barium sulfate $\left(\mathrm{BaSO}_{4}\right)$.

Pada penelitian ini, setelah dilakukan pengujian dengan alat XRD maka dilakukan dua kali analisa yaitu analisa kualitatif (software Match) dan analisa kuantitatif (software Fullpro). Pada analisa kualitatif, data hasil pengujian alat XRD ini kemudian dimasukkan kedalam program Match untuk mengetahui fasa kristal yang terbentuk. Didalam program match sudah terdapat database sesuai dengan ICDD-PDF. Dari program match secara otomatis akan muncul nama fasa kristal yang terbentuk yaitu barite.

Berikut hasil analisa dengan software Fullpro pada sampel kristal barium sulfate dengan konsentrasi larutan $3000 \mathrm{ppm} \mathrm{Ba}^{2+}$ aditif asam tartrat 0 ppm dengan sampel kristal barium sulfate dengan konsentrasi larutan $3000 \mathrm{ppm} \mathrm{Ba}^{2+}$ aditif asam tartrat 10 ppm dapat dilihat pada Gambar 6 dibawah ini.

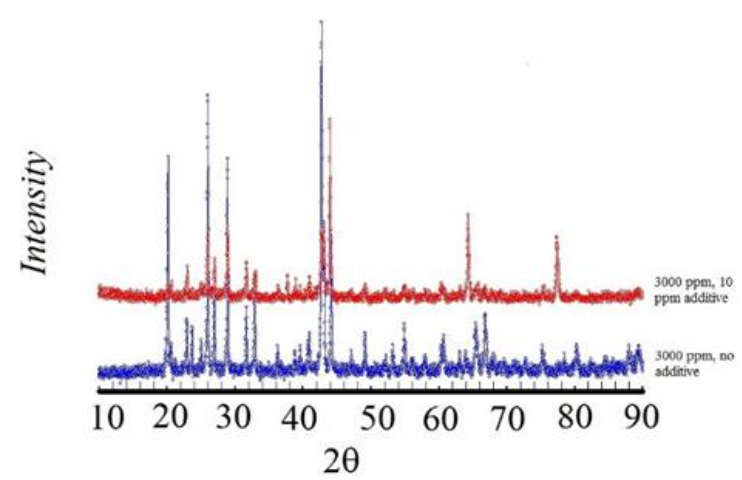

Gambar 6. Hasil uji XRD 


\section{SIMPULAN}

Dari hasil penelitian yang telah dilakukan pada kerak barium sulfate atau endapan kerak pada pipa pengeboran minyak bumi dapat disimpulkan bahwa dengan penambahan aditif atau penghambat kerak dapat mengurangi endapan massa kerak yang terjadi di dalam pipa dikarenakan dengan penambahan aditif maka bentuk morfologi kerak yang terjadi yaitu berbentuk runcing artinya kerak sulit menempel di dalam pipa sehingga dapat mengurangi terjadinya endapan kerak di dalam pipa pengeboran minyak bumi.

\section{DAFTAR PUSTAKA}

Asnawati. 2001. Pengaruh Temperatur Terhadap Reaksi Fosfonat dalam Inhibitor Kerak pada Sumur Minyak. Jurnal Ilmu Dasar. Vol.2. No.1:20.

Sousa, M.F., Bertran, C.A. (2014). New methodology based on static light scattering measurements for evaluation of inhibitors for in bulk crystallization. Journal of Colloid and Interface Science, 420, 57-64.

F. Jones, A. Oliveira, A.L. Rohl, G.M Parkinson, M.I. Ogden, M.M. Reyhani. (2002). Investigation into the effect of phosphonate inhibitors on barium sulfate preciptitation. Journal of Crystal Growth. 237-239.

Emel Akyol, Muala Oner. (2016). Control of Barium sulfate Crystallization in the presence of additives. ResearchGate.

Amer Badr Bin Merdhah, Abu Azam Mohd Yasin. (2009). Laboratory Study on Preciptation of Barium Sulphate in Malaysia Sandstone Cores. The Open Petroleum Engineering Journal. 1 - 11.

Robert J. Ferguson, Baron R. Ferguson. (2010). The Chemistry of Strontium and Barium Scales. Assosiation of Water Technologies.

Wang, Y. Moo, Y.X. Chen, C. Gunawan, P. Xu. P.G.R. (2010). Fast Preciptation of Uniform $\mathrm{CaCO}_{3}$ Nanospheres and Their Transformation to Hollow Hydroxyapatite Nanospheres. Journal of Colloid and Interface Science. 233. $65-72$.

Amer Badr Bin Merdhah. (2012). Inhibition of Barium sulfate Scale at HighBarium Formation Water. Journal of Petroleum Science and Engineering 90 $-91.124-130$.

G. Ivanto, F . Fatra, N S Dera, S. Muryanto, A P Bayuseno. (2017). Citric acid addition to controlling crystallization of barium suphate $\left(\mathrm{BaSO}_{4}\right)$ in pipes through $\mathrm{Ba}^{2+}$ concentration variation in the solution. The $4^{\text {th }}$ International Conference on Advanced Materials Science and Technology 